\title{
AGRICULTURA FAMILIAR, BIODIESEL E COMPETITIVIDADE: O CASO DO NÚCLEO DE PRODUÇÃO DE OLEAGINOSAS DE SERRA DO RAMALHO (BA)
}

\author{
Family Farming, Biodiesel and Competitiveness: \\ The Case of The Core of Serra do Ramalho Oilseeds Production (BA)
}

\begin{abstract}
RESUMO
Entre os principais objetivos do Programa Nacional de Produção e Uso do Biodiesel (PNPB) está a redução das desigualdades regionais com a inclusão de agricultores familiares na cadeia produtiva do biodiesel. Com isso, uma nova oportunidade despontou para os agricultores familiares de todo o país, especialmente nas regiões semiáridas do Norte e Nordeste. O presente trabalho teve como objetivo compreender os fatores que influenciam na competitividade da produção de mamona destinada ao programa de biodiesel pelos agricultores familiares do município de Serra do Ramalho, no estado da Bahia. Para tanto, foi realizado um estudo de caso descritivo com abordagem qualitativa, onde foram realizadas entrevistas semiestruturadas e aplicados questionários estruturados com os principais atores envolvidos na organização do Núcleo de Produção (NP-SR). No resultado obtido, constatou-se que fatores ligados à má gestão das propriedades rurais; baixa organização produtiva dos agricultores familiares; quebras dos contratos de compra e venda firmados; baixo nível tecnológico utilizado na produção da oleaginosa e; a logística deficiente de transporte e armazenamento contribuem significativamente para a baixa produção da mamona pelos agricultores familiares do NP-SR, reduzindo a sua competitividade. Para mudar este quadro, faz-se necessário uma redefinição dos papeis dos atores envolvidos, estimular boas práticas de gestão entre os agricultores familiares, investir na melhoria do nível tecnológico e da assistência técnica prestada e aumentar a fiscalização por parte dos agentes públicos.
\end{abstract}

Fábio Matos Fernandes

Universidade Federal da Bahia (UFBA)

fmatosf@gmail.com

Marcelo Santana Silva

Instituto Federal da Bahia (IFBA)

profmarceloifba@gmail.com

Luís Oscar Silva Martins

Universidade Federal do Recôncavo da Bahia (UFRB)

luisoscar@ufrb.edu.br

Francisco Gaudêncio Mendonça Freires

Universidade Federal da Bahia (UFBA)

francisco.gaudencio@ufba.br

Recebido em: 22/01/2021. Aprovado em: 14/09/2021.

Avaliado pelo sistema double blind review

Avaliador científico: Rafael Eduardo Chiodi

DOI: $10.48142 / 2320211752$

\begin{abstract}
Among the main objectives of the National Program for Production and Use of Biodiesel (PNPB), is the reduction of regional inequalities with the inclusion of family farmers in the biodiesel production chain. With this, a new opportunity has emerged for family farmers across the country, especially in the North and Northeast regions. This study aimed to understand the factors that influence the competitiveness of castor production for biodiesel by farmers of the Serra do Ramalho, in the Bahia estate. Therefore, we performed a descriptive case study with a qualitative approach, which were carried out semi-structured interviews and structured questionnaires with the main actors involved in the organization of the Production Center. The results, it was found that factors related to poor management of rural properties; low productive organization of family farmers; breaks the signed purchase and sales contracts; low level of technology used in the production of oilseeds; and poor logistics transport and storage significantly contribute to low production of castor seeds by farmers NP-SR, reducing their competitiveness. To change this situation, it is necessary to redefine the roles of the actors involved, encourage good management practices among farmers, invest in improving the technological level and provide technical assistance and increase supervision by public agents.
\end{abstract}

Palavras-chave: Cooperativismo; Produção de Mamona; Cadeia produtiva.

Keywords: Cooperativism; Castor Production; Productive Chain. 


\section{INTRODUÇÃO}

No Brasil, país notoriamente conhecido no cenário internacional por uma matriz energética diversificada, a utilização de fontes renováveis de energia representou $45,3 \%$ da sua oferta interna de energia em 2018 graças à utilização biomassa da cana com 17,4\%; da hidráulica e eletricidade com $12,6 \%$; da lenha e carvão vegetal com 8,4\%; da lixívia e outras renováveis com 6,9\% (EPE, 2019).

Neste cenário, o governo brasileiro realizou uma série de estudos para ampliar a sua matriz energética renovável com destaque para o Programa Nacional de Produção e Uso do Biodiesel (PNPB), criado em 2005 para regular o mercado de biodiesel, estabelecer uma trajetória de aumentos compulsórios para seu uso comercial no país e incluir os agricultores familiares nesta cadeia produtiva (MDA, 2012a).

Quanto ao estímulo à agricultura familiar, foi criado o Selo Combustível Social (SCS), uma identificação fornecida às usinas de biodiesel para conferir o caráter de agente de inclusão social dos agricultores familiares enquadrados Programa Nacional de Agricultura Familiar (PRONAF). Em 2019, o país contabilizava 51 usinas de biodiesel aptas a operar comercialmente do ponto de vista legal e regulatório e com capacidade instalada de produção de biodiesel de $9.450 \mathrm{mil} \mathrm{m}^{3} /$ ano. Dessas, 40 detinham o Selo Combustível Social (ANP, 2020).

Apesar de $80 \%$ das usinas possuírem o selo e do aparente sucesso na inclusão da agricultura familiar no PNPB, dificuldades para inserção de agricultores familiares na cadeia produtiva do biodiesel ainda são observadas (Conejero et al., 2017; De Oliveira et al., 2019; Ribeiro et al., 2018), especialmente os da região Nordeste, como ocorreu no Território de Identidade Velho Chico, formado por 16 municípios e que ocupam uma área de $47.834,80 \mathrm{Km}^{2}$ na região econômica do Médio São Francisco no Estado da Bahia, semiárido do Nordeste (SEI, 2010).

Assim como ocorre com as demais regiões integrantes do semiárido brasileiro, o Território de Identidade Velho Chico é altamente dependente do poder público, pois apresenta um baixo Índice de Desenvolvimento Sustentável (0,340), possuindo 118.493 pessoas em situação de extrema pobreza e 140.281 beneficiários de Bolsa Família em 2010 (MDA, 2012a).

Dentre os municípios integrantes do Território de Identidade Velho Chico, encontra-se Serra do Ramalho, que surgiu a partir da estruturação de um Projeto Especial de Colonização do Instituto Nacional de Colonização e Reforma Agrária (INCRA) para receber famílias de camponeses desalojadas pela construção da represa de Sobradinho (BA) na década de 1970 (Estrela, 2006).

Em Serra do Ramalho, estima-se que 25.475 habitantes $(81,23 \%$ da população) vivem em áreas rurais, fazendo da agricultura a principal atividade econômica do município (IBGE, 2021). Os agentes envolvidos com o PNPB viram uma oportunidade de melhorar as condições de vida desta população, em especial dos agricultores familiares estimados em 2.974 (MDA, 2012b), estimulando-os a aderirem ao programa através do cultivo e venda da mamona (Ricinus communis).

Um núcleo de produção foi instalado em agosto de 2008, chamado de Núcleo de Produção de Serra do Ramalho (NP-SR) ${ }^{1}$. Os resultados foram positivos nas safras de 2008/2009 a 2010/2011, porém nas safras seguintes os resultados não foram satisfatórios e as dificuldades para produzir e comercializar tornaram-se cada vez maiores.

Diante do exposto, este estudo tem como finalidade responder a seguinte questão norteadora: Quais fatores estão relacionados com a competitividade da produção de mamona destinada ao programa de biodiesel pelos agricultores familiares do NP-SR?

Diante do problema levantado, o objetivo deste trabalho é compreender os fatores que influenciam na competitividade da produção de mamona destinada ao programa de biodiesel pelos agricultores familiares do NP-SR. Especificamente, levantar os fatores que implicam positiva ou negativamente na produção da mamona pelos agricultores familiares do NP-SR, de acordo com a percepção dos atores locais envolvidos com o PNPB, bem como sugerir possíveis proposições para viabilizar a produção de mamona destinada ao PNPB pelos agricultores familiares do NP-SR.

Este trabalho está dividido em mais cinco seções além desta introdução. Na seção dois foi comentado brevemente sobre a produção de biodiesel e sua função social, por meio do Selo Combustível Social. A seguir, na seção três, foi introduzido os modelos de direcionadores de competitividade. Na parte quatro foram demonstrados os métodos e técnicas de pesquisa. Na seção cinco foi realizada toda apresentação, análise e discussão dos resultados encontrados e finalmente, na seção seis foram apresentadas as considerações finais.

\footnotetext{
${ }^{1}$ O Núcleo foi criado e estimulado pelo Sindicato de Trabalhadores Rurais de Serra do Ramalho em 2008. No entanto, com o passar dos períodos, o núcleo se afastou do sindicato e se aproximou mais das usinas. Nota dos Autores (2020).
} 


\section{BIODIESEL E SELO COMBUSTÍVEL SOCIAL}

De uma maneira geral, pode-se dizer que as principais fontes energéticas das atividades produtivas contemporâneas advêm dos combustíveis fósseis, e o uso intensivo destes, provoca graves efeitos sobre o meio ambiente, uma vez que sua queima produz grandes quantidades de gases geradores do efeito estufa, em especial Dióxido de Carbono $\left(\mathrm{CO}_{2}\right)$, contribuindo para o agravamento das mudanças climáticas (Borges et al., 2016; M. A. Lima et al., 2020; Zheng et al., 2020)caused mainly by emissions of Greenhouse Gases (GHG's.

Por este motivo, governos, empresas e a sociedade civil organizada têm discutido cada vez mais sobre a inserção e o aumento da participação das fontes renováveis de energia nas suas matrizes energéticas (Lima et al., 2019; Lopes et al., 2019; Rocha et al., 2015).

Entre as fontes renováveis de energia, destacam-se os biocombustíveis, obtidos a partir da biomassa, matéria orgânica existente em um ecossistema ou em uma população animal ou vegetal (Pinto et al., 2005; Singh et al., 2020).

Existem diferentes tipos de biocombustíveis que podem ser produzidos a partir da biomassa como o biodiesel que, em termos químicos, trata-se de uma mistura de ésteres alquílicos de ácidos graxos, podendo ser produzido a partir de óleos extraídos de vegetais, de gorduras residuais ou de gorduras animais (De Oliveira \& Coelho, 2017; Guarieiro et al., 2011; Sánchez et al., 2018).

$\mathrm{O}$ marco regulatório do biodiesel engloba um conjunto de leis que norteiam as ações, estabelecem as condições legais para a sua introdução na matriz energética brasileira e considera que a ampliação da produção e consumo seja feita de forma gradativa, levando em conta a diversidade e disponibilidade de oleaginosas, a garantia do suprimento, a qualidade e a competitividade frente aos demais combustíveis. Também considera o aspecto social com enfoque na inclusão social e no desenvolvimento regional, via geração de emprego e renda (Olave et al., 2017; M. S. Silva, Teixeira, Torres, Rocha, et al., 2014).

O SCS é o principal instrumento de promoção social do PNPB. Ele é concedido ao produtor de biodiesel que, voluntariamente, decide cumprir os critérios descritos em sua norma vigente, conferindo-lhe o status de promotor da inclusão social dos agricultores familiares enquadrados no PRONAF, ao possibilitar que estes participem do mercado de combustíveis nacional, fornecendo matériasprimas para a produção de biodiesel (MDA, 2012a).

Para conseguir, manter e usar o selo, o produtor de biodiesel deve cumprir uma série de critérios e procedimentos regulamentados. Entre os critérios estabelecidos, está a obrigatoriedade de aquisição de um percentual mínimo de matéria-prima proveniente da agricultura familiar no ano de produção do biodiesel de acordo com as regiões brasileiras (MDA, 2012a).

Outras vantagens são a possibilidade de explorar a marca do SCS para promover sua imagem no mercado, a diferenciação/isenção nos tributos PIS/Pasep e Cofins, acesso às melhores condições de financiamento junto aos bancos que operam o programa e ter participação assegurada de $80 \%$ do biodiesel negociado nos leilões públicos da Agência Nacional de Petróleo, Gás Natural e Biocombustíveis - ANP (Abicht et al., 2014; dos Santos Alves et al., 2017; Moreno-Pérez et al., 2017).

Diversos autores tecem algumas críticas quando dizem que o SCS teve um baixo impacto no desenvolvimento regional, não conseguindo cumprir as metas sociais de inserção de agricultores familiares nas regiões Norte e Nordeste, respaldados nos trabalhos de Silva, et al. (2014), Alves et al. (2017), Ribeiro et al. (2018) e De Oliveira et al. (2019).

\section{MODELO DOS DIRECIONADORES DE COMPETITIVIDADE}

A competitividade pode ser entendida como a capacidade de uma empresa formular e interpretar estratégias competitivas que lhe permitam ampliar ou conservar, de forma duradoura, uma posição sustentável no mercado (Ferraz et al., 1995).

Ela também pode ser vista como a capacidade de um dado sistema produtivo obter rentabilidade de maneira sustentada, bem como manter sua participação de mercado (Batalha \& da Silva, 2008).

Como pode ser observado nas definições apresentadas, não há um consenso conceitual para definir competitividade, o que pode levar a ambiguidades e impactar na forma de estabelecer metodologias mais adequadas para sua análise (Batalha \& da Silva, 2008; Farina, 1999; Ferraz et al., 1995).

Com relação aos métodos de análise da competitividade e identificação dos principais fatores que a afetam, a literatura acadêmica apresenta uma série modelos que podem ser adotados a depende de quais agentes ou setores econômicos estudados.

No caso das cadeias produtivas agroindustriais, um dos métodos utilizados é o Modelo dos Direcionadores de Competitividade, desenvolvido por (Van Duren et al., 1991) que contempla uma série de indicadores caraterísticos do agronegócio e os impactos causados por quatro grandes grupos de fatores na competitividade, a saber: 
a) fatores controláveis pela firma: sofrem influência direta da gestão empresarial (estratégias, produtos, tecnologia, políticas de recursos humanos, pesquisa e desenvolvimento e outros);

b) fatores controláveis pelo governo: compreendem medidas que vão além do escopo das empresas e que podem melhorar a competitividade (políticas fiscais e monetárias, política educacional e leis de regulação para o mercado e outros);

c) fatores quase-controláveis: a firma e/ou ações governamentais têm parcial influência (preço de insumos, condições da demanda, competição entre os agentes, poder de barganha entre fornecedores e clientes e outros).

d) fatores não controláveis: afetam a competitividade e não podem ser previstos com exatidão, e muito menos, controlados pela firma (fenômenos naturais e climáticos).

No Brasil, o método apresentado por Van Duren, Martin \& Westgren (1991) foi adaptado por Batalha \& Silva (2008), que levaram em consideração às especificidades das cadeias agroindustriais locais.

Eles propuseram a visualização das atividades agropecuárias como partes de um sistema mais amplo que inclui atividades a montante e a jusante da cadeia, inseridas em um dado ambiente institucional e organizacional. Com isso, além da avaliação da competitividade e seu diagnóstico, proposições de políticas públicas e/ou privadas poderiam ser estimuladas para minimizar as dificuldades e potencializar as vantagens competitivas empresariais (Batalha \& Souza Filho, 2009; Shultz et al., 2011).

Para que isto fosse possível, Batalha \& Silva (2008) estabeleceram uma série de elementos que funcionam como mecanismos de avaliação e medição denominados de direcionadores de competitividade.

Segundo os autores, estes direcionadores afetam significativamente o desempenho da maioria das cadeias agroindustriais, pois envolvem uma ampla variedade de dimensões que por conveniência analítica, foram agregadas em: ambiente institucional, estrutura de governança, tecnologia, estrutura de mercado, gestão da firma e insumos. Essas dimensões foram utilizadas para diagnosticar o ambiente estratégico do NP-SR, e detalhadas nas seções metodológicas e de resultados e discussão.

\section{METODOLOGIA}

Este trabalho caracteriza-se como qualitativo descritivo, cujo procedimento técnico adotado foi o estudo de caso com aplicação do modelo de análise da competitividade proposto por Batalha \& Silva (2008), que se desdobrou em três etapas.
Na primeira etapa foi realizado um levantamento bibliográfico que permitiu caracterizar a cadeia produtiva agroindustrial do biodiesel, o selo combustível social e o modelo de competitividade aplicada ao estudo.

$\mathrm{Na}$ segunda etapa foram selecionados por conveniência analítica os direcionadores: insumos, tecnologia de produção, gestão, estrutura de produção, relação de mercado e ambiente institucional e, em seguida, estabelecidos 23 subfatores correspondentes para cada direcionador como mostra o Quadro 1.

$\mathrm{Na}$ terceira e última etapa foi avaliado o impacto gerado pelos subfatores e sua contribuição para o efeito agregado no desempenho dos direcionadores de competitividade.

O lócus da pesquisa foi o NP-SR, onde foram realizadas coletas de dados primários através da realização de entrevistas semiestruturadas e aplicação de questionários com 19 participantes da pesquisa. A escolha dos participantes levou em consideração o conhecimento que eles possuíam sobre o programa de biodiesel e o envolvimento dos mesmos na produção da mamona no referido núcleo.

Vale ressaltar que nenhuma organização ou pessoa foi identificada, conforme pedido formalizado pelos participantes no Termo de Consentimento Informado.

Também foram utilizadas técnicas de observação para obtenção de dados primários durante toda a pesquisa de campo. Com isso, foi possível conhecer, in loco, as atividades de produção da mamona pelos agricultores, os relacionamentos destes com os demais atores do NP-SR (sindicato, banco, cooperativas, técnicos agrícolas e outros), as condições logísticas relacionadas ao transporte, armazenamento da safra e infraestrutura local.

Por fim, todos os dados obtidos foram triangulados para possibilitar a máxima amplitude na descrição, explicação e compreensão do fenômeno estudado. Desta maneira, as entrevistas realizadas foram analisadas em conjunto com as notas das observações feitas em campo e com as respostas obtidas nos questionários estruturados, tratados com software Microsoft Excel 2010.

Neste tratamento, foi utilizada a escala Likert apresentada no questionário, onde foi recebida uma nota, como mostra a Tabela 1.

Em seguida, foram obtidas as frequências das respostas dadas para cada subfator. Estas, por sua vez, foram multiplicadas pelas notas correspondentes (Tabela 1). Realizou-se então a divisão do resultado da multiplicação pela base total da amostra (frequência total), obtendo a média para cada subfator. 
QUADRO 1 - Direcionadores e subfatores de competitividade utilizados na pesquisa

\begin{tabular}{|c|c|}
\hline $\begin{array}{l}\text { Direcionadores de } \\
\text { Competitividade }\end{array}$ & Subfatores de Competitividade \\
\hline Insumos & $\begin{array}{l}\text { Sementes utilizadas } \\
\text { Disponibilidade de sementes } \\
\text { Disponibilidade de outros insumos } \\
\text { Disponibilidade de máquinas e implementos agrícolas }\end{array}$ \\
\hline $\begin{array}{l}\text { Tecnologia de } \\
\text { produção }\end{array}$ & $\begin{array}{l}\text { Sistema de produção } \\
\text { Práticas de manejo do solo } \\
\text { Tratos culturais } \\
\text { Práticas de controle de pragas e doenças } \\
\text { Nível de mecanização }\end{array}$ \\
\hline Gestão & $\begin{array}{l}\text { Administração da propriedade } \\
\text { Organização produtiva dos agricultores familiares } \\
\text { Assistência técnica }\end{array}$ \\
\hline Estrutura de produção & $\begin{array}{l}\text { Condições edafoclimáticas } \\
\text { Disponibilidade de terras } \\
\text { Oferta de mão-de-obra } \\
\text { Infraestrutura de transporte e armazenamento da safra }\end{array}$ \\
\hline Relação de mercado & $\begin{array}{l}\text { Assinatura e cumprimento dos contratos de compra e venda da matéria-prima } \\
\text { Forma e o prazo de liberação do pagamento da safra adquirida pela empresa produtora } \\
\text { Atuação dos intermediários } \\
\text { Acesso ao crédito para financiar a produção }\end{array}$ \\
\hline Ambiente institucional & $\begin{array}{l}\text { Fiscalização } \\
\text { Assistência prestada pelos órgãos governamentais } \\
\text { Políticas públicas para a inserção dos agricultores familiares na Cadeia Produtiva do Biodiesel - CPB. }\end{array}$ \\
\hline
\end{tabular}

Fonte: Elaborado pelos autores com base no modelo dos direcionadores de competitividade propostos por Batalha \& Silva (2008)

TABELA 1 - Notas para as alternativas da escala Likert

\begin{tabular}{lc}
\hline \multicolumn{1}{c}{ Alternativas da escala } & Notas correspondentes \\
\hline Muito Desfavorável (MD) & -2 \\
Desfavorável (D) & -1 \\
Neutro (N) & 0 \\
Favorável (F) & 1 \\
Muito Favorável (MF) & 2 \\
\hline
\end{tabular}

Fonte: Elaborado pelos autores (2019)

Como os subfatores apresentam diferentes graus de importância, Batalha e Silva (2008) recomendam individualizá-los. Assim, após a realização das entrevistas e das observações feitas em campo foi atribuído um peso para cada subfator.

Com isso, a média ponderada de cada direcionador com base nos pesos atribuídos aos subfatores foi calculada. De posse das informações obtidas com as entrevistas, notas das observações, do material bibliográfico e da tabulação dos questionários, realizou-se a análise por meio da triangulação com o intuito de fortalecer os resultados da pesquisa.

\section{ANÁLISE E DISCUSSÃO DOS RESULTADOS DA PESQUISA}

No início da década de 1970, o Brasil vivia sob o domínio do regime militar e vivenciava o seu "milagre econômico" com altas taxas de crescimento e internacionalização da economia. Neste período, foram executadas várias obras de infraestrutura, entre as quais estava a construção da Represa de Sobradinho, que tinha como objetivo aumentar a capacidade do setor elétrico do Nordeste.

Anecessidade de reassentar os moradores desalojados das regiões afetadas levou o governo, através do INCRA, em 1973, a decretar a região do Médio São Francisco como área prioritária para desapropriação. Uma extensa área entre os municípios de Bom Jesus da Lapa e Carinhanha foi desapropriada para abrigar um Projeto Especial de Colonização (PEC), nascia o PEC de Serra do Ramalho. 
Este PEC foi concebido para abrigar cerca de 4.000 famílias e estruturado em formato de agrovilas, separando o local de trabalho (roça) do local de moradia e abrigava ainda uma reserva extrativista, uma vez que a atividade pecuária era proibida nos lotes. No projeto original, eram 16 agrovilas separadas uma das outras a cada seis ou sete quilômetros. Além disso, cada agrovila deveria abrigar toda a infraestrutura de comércio e serviços.

Nos anos de 1976 e 1977, tem-se o reassentamento de 1.029 famílias de um total de 1.600 cadastradas. Cada família recebeu um módulo rural de 20 hectares, um lote urbano com uma casa na agrovila próxima do seu trabalho e cinco hectares na reserva extrativista. Posteriormente, o INCRA também alocou os sem-terra, oriundos de outros pontos da Bahia, do Nordeste e até do Centro-Sul (Estrela, 2006).

Em 1989, o PEC de Serra do Ramalho foi elevado à categoria de município. Está localizado a $830 \mathrm{~km}$ de Salvador (BA) no semiárido baiano, na microrregião geográfica de Bom Jesus da Lapa e integra o Território de Identidade Velho Chico. Possui uma área de 2.677,37 $\mathrm{Km}^{2}$, que foi dividida em quatro eixos latitudinais: Eixo 1 - agrovilas 1, 3, 5, 7, 9 e 11; Eixo 2 - agrovilas 2, 4, 6, 8, 10, 12, 13 e 14; Eixo 3 - agrovilas 17, 18, 21 e 22 e; Eixo 4 - agrovilas 19 e 20. Dentro dos limites municipais encontram-se os projetos de assentamento de reforma agrária CSB, Reserva Oeste e Extrativista São Francisco, além de uma aldeia do povo indígena Pankaru (Estrela, 2006; SEI, 2010).

Em 2010, Serra do Ramalho tinha uma população estimada em 31.638 habitantes, sendo que 25.364 habitantes residiam em áreas rurais, o que corresponde a cerca de $80 \%$ do total de habitantes. O município conta ainda com 2.974 estabelecimentos da agricultura familiar e 1.437 famílias assentadas (IBGE, 2021; MDA, 2012b).

Segundo os entrevistados, na década de 1990, a cultura da mamona foi introduzida no município de Serra do Ramalho como uma alternativa de renda para os pequenos agricultores devido ao baixo custo de implementação, fácil cultivo, boa adaptabilidade ao clima e solo da região e facilidade de comercialização (liquidez).

Foi apontado como principal motivo a falta de interesse dos representantes da empresa e da cooperativa em recolher a produção, estimada em 19 toneladas, por não ser economicamente viável devido à pulverização dos locais de produção. Fato que ocorreu em outras regiões em que a empresa atuou, a exemplo da Serra Capivara, no Estado do Piauí, como constatado por Brune (2010).

Em agosto de 2008 foi criado o núcleo de produção de oleaginosa de Serra do Ramalho (NP-SR). Criou-se um grupo de trabalho para mobilizar os agricultores familiares locais a aderirem ao PNPB, recuperar a confiança daqueles que produziram e não comercializaram a safra anterior e estabelecer um plano estratégico que levasse a criação de um ambiente favorável para a produção da mamona.

Foram cadastrados mais de 2.000 agricultores familiares aptos para o cultivo da mamona. Desse total, cerca de 600 aderiram à produção da oleaginosa já na safra 2008-2009, chegando a 990 nas safras seguintes.

\subsection{Fatores que Implicam Positiva ou Negativamente na Competitividade do NP-SR}

Nesta subseção foram identificados os fatores que implicam positivamente e negativamente na competitividade do NP-SR, a partir dos direcionadores de competitividade, bem como, na pesquisa realizada. Foram destacados os seguintes direcionadores: Insumo, Tecnologia da produção, Gestão, Estrutura da Produção, Relação de Mercado, Ambiente Institucional e seus subfatores.

\subsubsection{Direcionador Insumos e seus subfatores}

O direcionador de competitividade insumos foi dividido em quatro subfatores: sementes utilizadas; disponibilidades das sementes; disponibilidade de defensivos agrícolas e disponibilidade de máquinas e implementos agrícolas. Com exceção do subfator sementes utilizadas, todos os demais foram percebidos pelos entrevistados como negativos com mostra a Figura 1.

O subfator sementes utilizadas foi percebido como muito favorável, pois antes da criação do NP-SR as sementes de mamona utilizadas eram as bagas da safra anterior, colhidas pelos próprios agricultores. Prática que reduz a produtividade, uma vez que as sementes não apresentam boa germinação, favorece o surgimento de impurezas, problemas fitossanitários e fisiológicos, além de propiciar a formação de um estande não uniforme (Campos et al., 2009; César \& Batalha, 2011).

Sementes certificadas da variedade BRS 149 Nordestina foram distribuídas por possuir boa produtividade e tolerância à seca, o que reflete o posicionamento de Cartaxo et al. (2011) quando afirma que esta variedade se adapta bem nas regiões semiáridas e ao sistema produtivo manual, características do NP-SR.

Já a disponibilidade das sementes foi muito criticada. Para os entrevistados, desde a criação do núcleo este insumo era distribuído tardiamente, às vezes no mês de janeiro, fora do zoneamento agrícola, que na região tem início em $1^{\circ}$ de novembro e termina 20 de dezembro (EMBRAPA, 2012). 


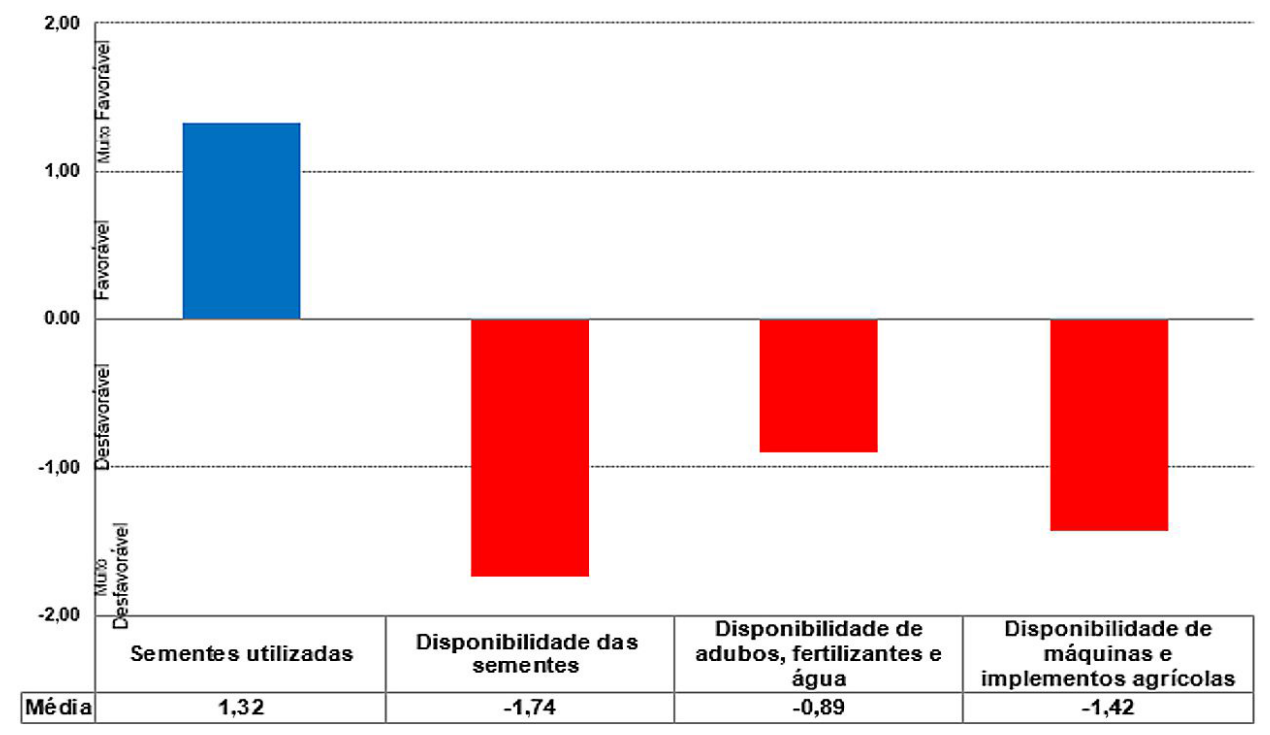

FIGURA 1 - Avaliação dos subfatores do direcionador de competitividade insumos Fonte: Elaborado pelos autores (2019)

A crença de que a cultura da mamona não carece de muitos cuidados é disseminada, fazendo com que os agricultores familiares utilizem somente adubos orgânicos: esterco de bovinos e a própria casca da mamona.

Por fim, o subfator disponibilidade de máquinas e implementos agrícolas foi percebido como muito desfavoráveis. Todos os entrevistados afirmaram que a quantidade disponibilizada não era suficiente para atender a demanda, ocasionado atrasos no plantio.

O maquinário utilizado na preparação dos solos foi considerado inadequado por se tratar de tratores pequenos com pouca potência, que não garantem o correto atendimento da execução das tarefas - aragem, gradagem e subsolagem.

Já o número insuficiente de descascadoras mecânicas, aliado a falta de um planejamento logístico e a pulverização das propriedades rurais tornaram os atrasos no beneficiamento uma constante. Com isso, muitos agricultores familiares viam-se obrigados a buscar ajuda de intermediários que levavam os descascadores até os estabelecimentos rurais para fazer o beneficiamento, mas pagavam um valor menor do que a cotação de mercado para adquirir a mamona.

\subsubsection{Direcionador Tecnologia de produção e seus subfatores}

Neste estudo, o direcionador da tecnologia de produção levou em consideração somente as tecnologias adotadas no processo produtivo, sendo desmembradas em cinco subfatores: sistema de produção, práticas de manejo do solo, práticas de controle de pragas e doenças, tratos culturais e nível de mecanização (Figura 2).

O subfator sistema de produção foi percebido como favorável. Contribuíram para esta percepção a forma como a mamona é produzida no NP-SR: de sequeiro e consorciada com feijão, possibilitando mais uma complementação de renda para o agricultor ou redução nos custos com tratos culturais, especialmente a capina, já que a produção de feijão é dividida com terceiros, responsáveis pela atividade.

Já o subfator 'práticas de manejo do solo' foi percebido como muito desfavorável. Segundo os entrevistados, a análise e correção do solo não é uma prática usual e valorizada pelos agricultores. O manejo do solo para receber o plantio da mamona no NP-SR é feito de maneira muito rudimentar, geralmente com o uso de queimadas para preparar o terreno e não adoção de práticas de prevenção à erosão e aproveitamento da declividade natural para melhor aproveitamento das águas das chuvas.

Quanto aos tratos culturais, a EMBRAPA (2012) recomenda a realização de duas ou três capinas; a população de plantas deve ser definida pelo espaçamento entre linhas e distância de plantas dentro da linha, sendo que para locais muito secos deve-se permitir maior distância entre as plantas para diminuir a concorrência e; o desbaste deve ser feito entre 10 e 20 dias após a emergência. Foi observado que no NP-SR, todos estes tratos culturais são 
feitos com baixo nível de mecanização, mesmo assim, este subfator foi percebido como muito favorável.

A mesma percepção favorável obteve o subfator práticas de controle de pragas e doenças, pois não há registro de ocorrências de pragas e doenças que afetam o mamoneiro no NP-SR, o que dispensa o uso de defensivos agrícolas. Contudo, os técnicos agropecuários realizam o monitoramento periódico das plantas com o intuito de identificar possível incidência de pragas ou doenças.

Por fim, o subfator nível de mecanização foi considerado pelos entrevistados como um importante entrave, sendo percebido como muito desfavorável. No NP-SR, as máquinas e implementos mecanizados são utilizados, quando possível, somente nas etapas de preparo do solo e beneficiamento da safra. Plantio, tratos culturais e colheita são realizados com equipamentos manuais e, em menor proporção, com equipamentos movidos à tração animal. Utiliza-se ainda em algumas propriedades chicotes de borrachas, varas para debulha e peneiras para separar a casca da baga. Processos demorado e perigoso devido à toxicidade do produto pontuaram alguns entrevistados.

\subsubsection{Direcionador Gestão e seus subfatores}

Segundo Batalha et al. (2005), no âmbito da agricultura familiar, a gestão pode ser analisada por dois aspectos: a administração da propriedade rural propriamente dita e as organizações sociais (sindicatos, associações e cooperativas) que os agricultores participam.
Neste estudo, o direcionador 'gestão', além de analisar os dois aspectos propostos pelos autores supracitados, também analisa a assistência técnica disponibilizada para os agricultores como mostra a Figura 3.

O subfator Administração da propriedade foi percebido como muito desfavorável. Para Batalha et al. (2005), tradicionalmente, questões ligadas à administração são pouco utilizadas ou tratadas de forma insatisfatória nas propriedades rurais familiares, especialmente aquelas de menor porte. $\mathrm{O}$ agricultor tem maior preocupação com questões técnicas e operacionais relacionadas aos tratos culturais do que com administração.

Tal cenário foi encontrado no NP-SR, onde os agricultores não utilizam ferramentas de gestão, a exemplo do controle de custos, do planejamento e controle da produção e da logística. Segundo os entrevistados, a baixa escolaridade dos agricultores, associada à influência cultural de procurar resolver os problemas no curto prazo contribuem significativamente para a perpetuação deste quadro.

Cabe destacar que a mobilização dos agricultores para a estruturação do NP-SR limitou-se apenas na apresentação das vantagens da adesão ao PNPB e nas contrapartidas dadas pelas empresas compradoras da matéria-prima. Nenhum curso de capacitação para gestão de empreendimentos agrícolas foi disponibilizado para os agricultores, segundo os entrevistados, o que demonstra a carência e a urgência de trabalhar conteúdos relacionados à administração de propriedades rurais, principalmente no que se refere a custos de produção.

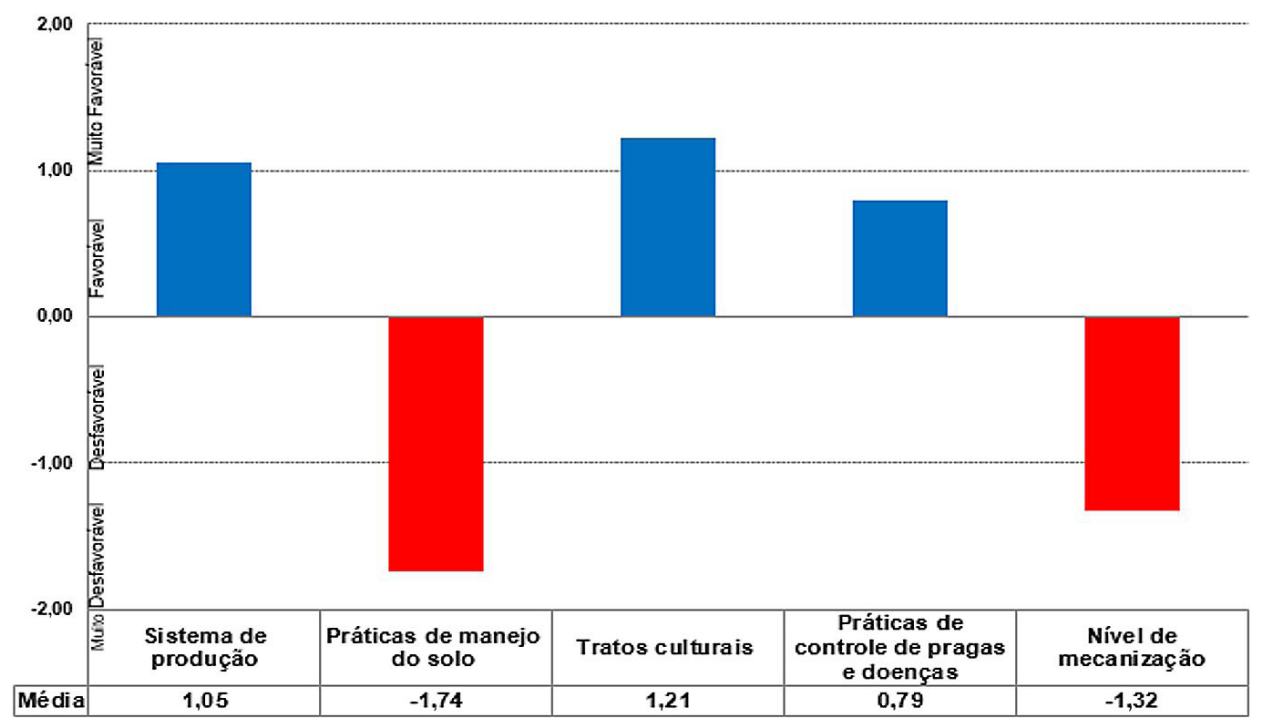

FIGURA 2 - Avaliação dos subfatores do direcionador de competitividade tecnologia de produção Fonte: Elaborado pelos autores (2019)

Organizações Rurais \& Agroindustriais, Lavras, v. 23, e1752, 2021 


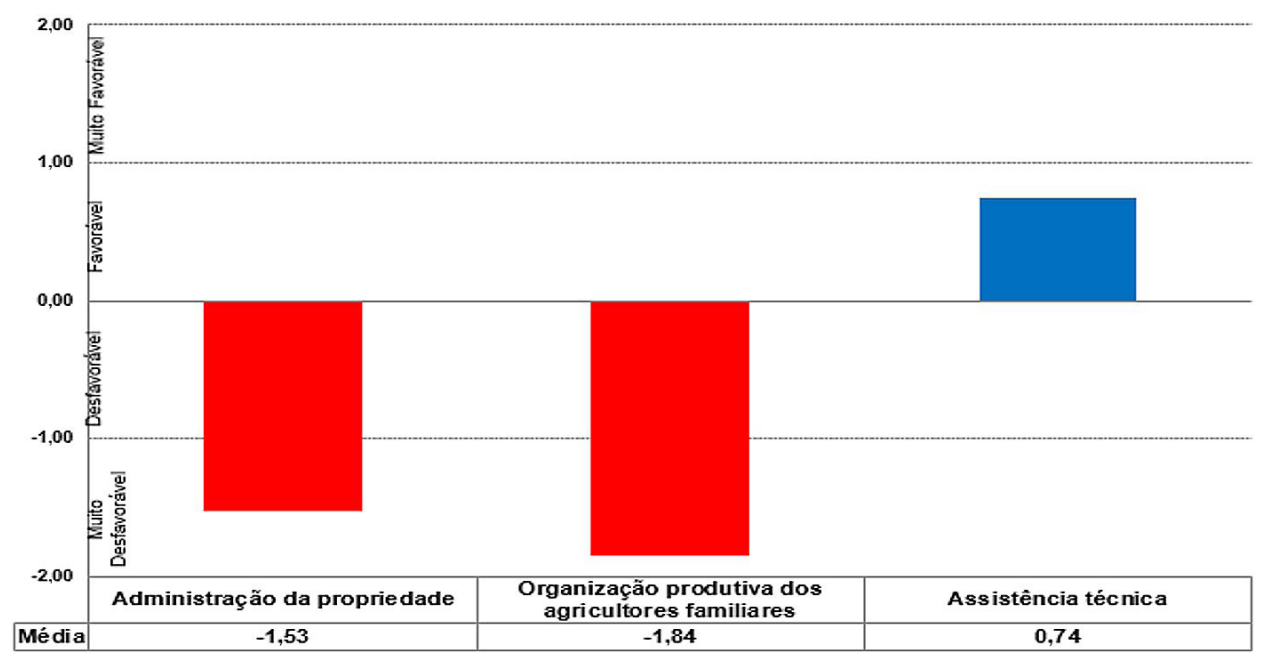

FIGURA 3 - Avaliação dos subfatores do direcionador de competitividade gestão Fonte: Elaborado pelos autores (2019)

Com relação aos custos de produção, constatou-se que o agricultor não leva em consideração o seu trabalho na execução das atividades relacionadas à preparação da terra, tratos culturais, colheita e beneficiamento, tornando equivocada a apuração do lucro obtido com a venda da safra.

O não conhecimento dos custos envolvidos na produção da mamona colabora para o uso inadequado dos recursos e para endividamento do agricultor. Conhecê-los é importante para que o agricultor compreenda o cenário em que está inserido, de acordo com César \& Batalha (2010).

Embora a organização produtiva dos agricultores familiares seja importante para o desenvolvimento rural e aumento da competitividade ao possibilitar o aumento do poder de barganha dos agricultores na hora de negociarem preços junto aos fornecedores de insumos e acesso a canais de distribuição nos quais, isoladamente, eles não poderiam participar, e neste aspecto, este subfator foi percebido como muito desfavorável devido quase inexistência no NP-SR.

Foi observado que o sindicato dos trabalhadores rurais apoiou as ações desenvolvidas pelas empresas envolvidas no PNPB. Entretanto, seu papel ficou restrito à fase de mobilização e emissão do documento que identifica os agricultores como sendo familiares (DAP). Para se ter uma ideia do isolamento do sindicato, este participou somente das negociações e fechamento de contratos entre empresas do PNPB e os agricultores na safra 2009-2010.

Quanto aos serviços de assistência técnica, estes foram prestados nas fases de cultivo, colheita e beneficiamento da mamona por técnicos terceirizados que ficam com a responsabilidade de acompanhar mais 100 famílias devido à dispersão geográfica dos agricultores no município. Fato também observado por Conejero et al. (2017) em outras regiões do Nordeste.

Para César \& Batalha (2010), atender um número de famílias além da recomendada pode dificultar ou impedir o desenvolvimento de relacionamento entre o técnico e o agricultor, comprometer a qualidade do acompanhamento do plantio e dificultar a assimilação de informações por parte do agricultor.

Para os técnicos, o maior problema enfrentado foi a resistência dos agricultores em adotar as recomendações disponibilizadas e continuarem com as práticas incorretas de manejo da cultura, comprometendo assim a sua produtividade. Atribui-se esta resistência a fatores culturais e a baixa escolaridade dos agricultores.

Apesar dos problemas encontrados, o subfator serviços de assistência técnica foi percebido como favorável.

\subsubsection{Direcionador Estrutura de Produção e seus subfatores}

Neste direcionador foram discutidas, a partir da percepção dos entrevistados (Figura 4), as condições edafoclimáticas encontradas na região para o cultivo da mamona, a disponibilidade de terras, a oferta de mão-de-obra e a infraestrutura logística, referente a transporte e armazenagem da safra.

Com relação às condições edafoclimáticas, a mamona exige chuvas regulares no início do plantio para um bom crescimento vegetativo (brotação e floração), com mínimo de $400 \mathrm{~mm}$ anuais e de períodos secos na fase de maturação dos frutos. $\mathrm{O}$ intervalo de temperatura ideal gira em torno de $20^{\circ}$ a $30^{\circ} \mathrm{C}$ e a umidade relativa do ar deve 
ser a menor possível para evitar a ocorrência de doenças. O solo deve apresentar boa topografia, ser profundo, bem drenado e com pH entre 6 e 7 (SEAGRI, 2012).

O NP-SR enquadra-se favoravelmente neste cenário, apresentando condições climáticas favoráveis, como boa insolação, devido aos dias longos, pluviosidade média de $685,6 \mathrm{~mm}$ anual, com chuvas no período de plantio - final de outubro, novembro e dezembro - e seca nos meses de colheita - junho, julho e agosto. A temperatura média anual é de $22,9{ }^{\circ} \mathrm{C}$ e grande parte dos solos são do tipo latossolo profundo (SEI, 2010). Estas características fizeram com que o subfator condições edafoclimáticos fosse percebido como muito favorável.

Quanto a disponibilidade de terras, observou-se que no NP-SR a maioria dos agricultores familiares são proprietários da terra, possuindo lotes que variam de 1 a 4 módulos fiscais ${ }^{2}$.

Aárea destinada para o plantio da mamona variava de 2 a 3 hectares para agricultores que possui um módulo fiscal e de 5 a 10 hectares para quem detém mais de um módulo fiscal. O restante da área é utilizado para o plantio de outras culturas temporárias como milho, feijão e sorgo, para pastagens destinadas a criação de animais ou ficam ociosas. Logo, a disponibilidade de terra para ampliação da área de cultivo da mamona fez com que este subfator fosse percebido como muito favorável.

2 Um módulo fiscal na região corresponde a 20 ha.
Já a mão-de-obra empregada no cultivo da mamona era essencialmente familiar em áreas de pequenas - 2 ou 3 ha - destinadas ao plantio da mamona. Em áreas superiores a 5 ha, contratam-se trabalhadores terceirizados, geralmente um ou dois, mediante ao pagamento de diárias.

O emprego da mão-de-obra terceirizada concentra-se na fase de tratos culturais até a planta atingir entre $1 \mathrm{~m}$ e $1,20 \mathrm{~m}$. Depois estes trabalhadores são dispensados, retornando no período da colheita e beneficiamento.

Quando o agricultor não tem capital para arcar com os custos da mão-de-obra ou tem dificuldade em captá-la, duas ou mais famílias se reúnem para realizar os trabalhos em esquema de mutirão (parceria), principalmente na fase da colheita e beneficiamento.

Embora César \& Batalha (2011) disserte sobre a oferta abundante e barata de mão-de-obra disponível para trabalhar na cultura da mamona na Bahia, no NP-SR o cenário encontrado difere deste posicionamento. Os entrevistados relataram a dificuldade para se contratar temporários, uma vez que muitos trabalhadores se deslocam para os estados do Sudeste ou Centro-Oeste em busca de melhores oportunidades. Outros preferem trabalhar no Perímetro de Irrigação Formoso ${ }^{3}$, pois as diárias pagas são maiores e o tempo para a realização da atividade laboral é menor, em torno de seis horas.

${ }^{3}$ Área destinada ao cultivo de banana, feijão, mandioca, coco, mamão e melancia que está compreendida entre a margem esquerda do rio São Francisco, margem direita do rio Corrente e a rodovia BA-349, que liga Bom Jesus da Lapa a Santa Maria da Vitória.

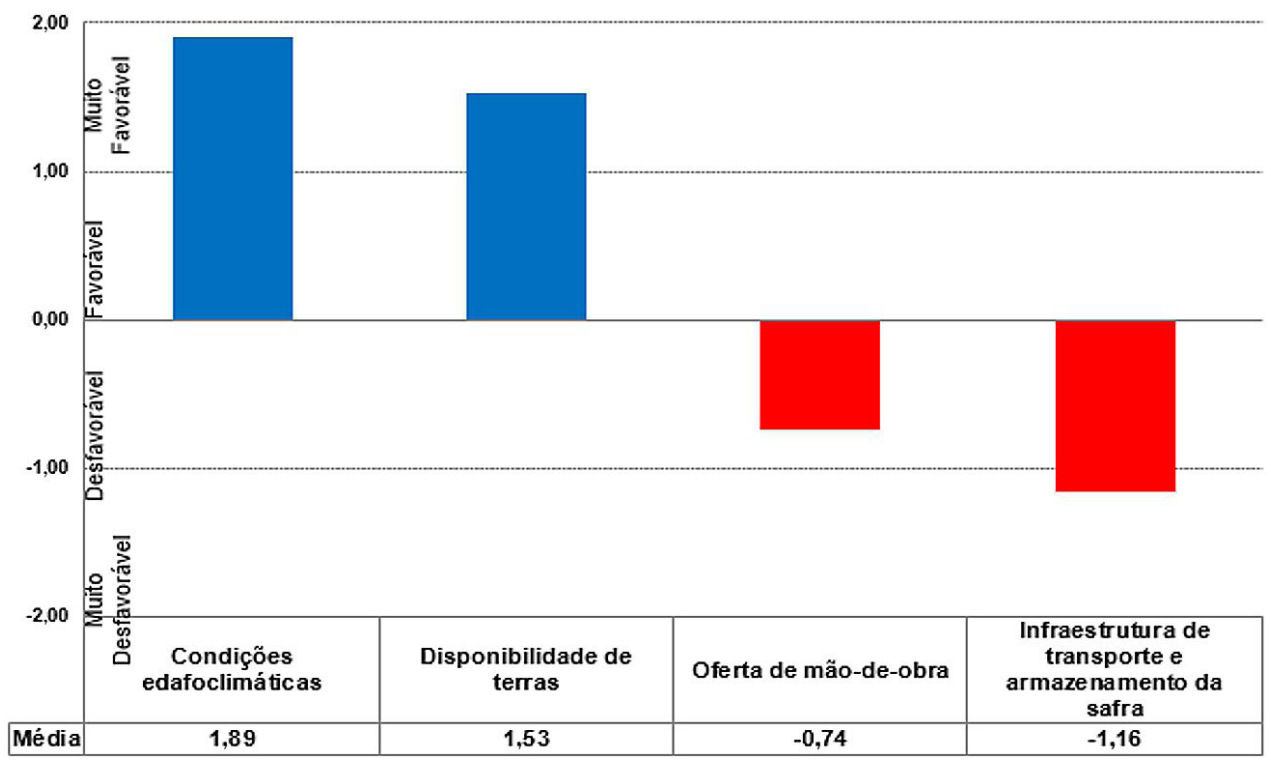

FIGURA 4 - Avaliação dos subfatores do direcionador de competitividade estrutura de produção Fonte: Elaborado pelos autores (2019)

Organizações Rurais \& Agroindustriais, Lavras, v. 23, e1752, 2021 
Cabe ressaltar que o recebimento de benefícios sociais e a elevação do nível educacional das pessoas mais jovens contribuíram para a dificuldade de contratação de temporários, fato também observado por Silva (2009).

Outra questão relacionada à mão-de-obra diz respeito a sua baixa escolaridade, o que compromete a adoção de novas tecnologias de plantio, refletindo na produtividade. Diante do exposto, este fator foi percebido como desfavorável.

Por fim, a infraestrutura logística relacionada ao armazenamento e transporte da mamona no NP-SR foi considerada um entrave. A dispersão geográfica dos agricultores aliada às más condições de trafegabilidade das estradas faz com que os insumos de produção e o recolhimento da safra sofram constantes atrasos. Além disso, o baixo volume de produção e a falta de um sistema de roteirizarão elevam os custos logísticos. Assim, este subfator foi percebido como muito desfavorável.

\subsubsection{Direcionador Relação de mercado e seus subfatores}

Este direcionador relaciona-se com a assinatura e cumprimento dos contratos de compra e venda de matéria-prima entre as empresas ou seus representantes junto aos agricultores familiares; a forma e o prazo de liberação do dinheiro para os agricultores; a ação dos intermediários no NP-SR e o acesso dos agricultores ao crédito bancário (Figura 5).
Com relação aos contratos de compra e venda de matérias-primas, a Portaria do MDA n ${ }^{\circ}$ 60/2012 estabelece que estes devem ser firmados com todos os agricultores familiares ou suas cooperativas. Além disso, as negociações incluem a participação de pelo menos uma representação dos agricultores (MDA, 2012a).

Todos os entrevistados consideraram este instrumento como uma importante conquista para a inclusão dos agricultores na $\mathrm{CPB}$ e um estímulo à produção da mamona no NP-SR, pelo fato de apresentar uma série de vantagens como: compra garantida com adoção de um preço mínimo de compra, que leva em consideração a cotação da mamona praticada na praça de Irecê (BA); assistência técnica e fornecimento de insumos (sementes e empréstimo de sacaria e máquinas para debulha).

Com relação ao preço mínimo estabelecido, este poderia aumentar caso, no momento da comercialização, o preço praticado pelo mercado de referência fosse superior ao estabelecido. Contudo, as empresas compradoras quase sempre não pagavam a diferença total. A falta de informação dos agricultores sobre a variação de preços das commodities agrícolas e o não envolvimento ou exclusão dos demais agentes integrantes do NP-SR nas negociações para fechamento dos contratos contribuíram para que esta situação ocorresse. Ademais, os agricultores não possuíam cópias dos contratos firmados, o que impossibilitava qualquer forma de fiscalização.

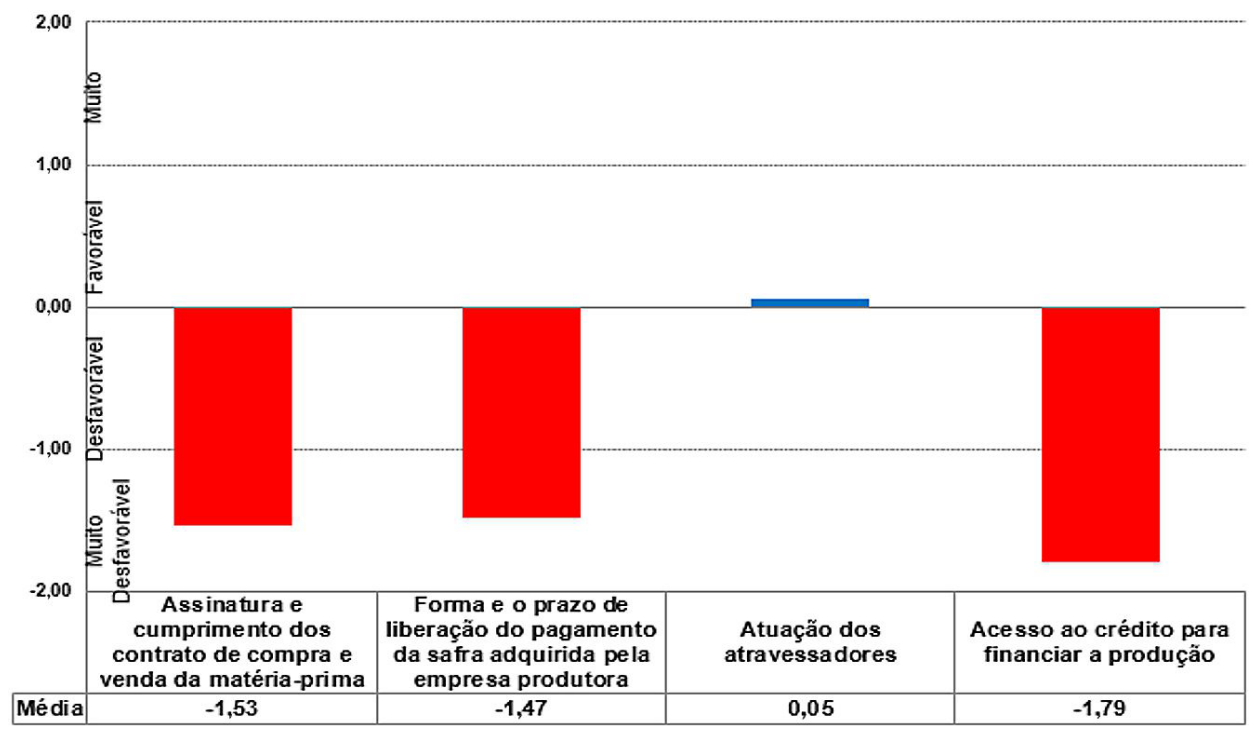

FIGURA 5 - Avaliação dos subfatores do direcionador de competitividade relação de mercado Fonte: Elaborado pelos autores (2019) 
A quebra de contrato dava-se dos dois lados. As empresas não honraram o compromisso de compra da mamona devido ao baixo volume de produção que encareciam o produto devido à logística de transporte e os próprios agricultores, em busca de retorno financeiro mais rápido, vendiam a produção para intermediários mesmo com a imposição de multas que chegam a $10 \%$ do valor resultante das quantidades estimadas de produção, fatos estes observados por Silva et.al. (2014b).

A quebra mútua dos contratos gerou desconfiança entre os atores, contribuiu para a redução na produção da mamona e comprometeu o funcionamento do NP-SR. Fato observado também por Abicht et al. (2014). Assim esse subfator foi percebido como muito desfavorável.

A forma e o prazo de liberação do pagamento da safra adquirida pela empresa produtora no NP-SR eram feitos através de depósito em conta para quem é cliente do Banco do Brasil ou diretamente ao agricultor, mediante a apresentação da identidade. O prazo para liberação do dinheiro varia entre 7 e 15 dias, podendo chegar a 30 dias, como relataram alguns agricultores. O prazo para liberação do dinheiro é considerado longo demais e favorece a ação dos intermediários, que se deslocam até as propriedades rurais e adquirem a produção, pagando à vista e às vezes com preço melhor do que os negociados em contrato.

Por este motivo, a forma e o prazo de pagamento, estabelecidos pela empresa produtora de biodiesel e pelas cooperativas, foram considerados como muito desfavoráveis.

Assim como ocorre em outros núcleos de produção de matéria-prima para o biodiesel, a atuação de intermediários também se fez presente no NP-SR e o papel desempenhado por estes agentes no NP-SR dividiu as opiniões dos entrevistados.

Representantes das cooperativas acusaram os intermediários de incentivarem a quebrarem os contratos firmados, pagando, a depender da cotação, preços melhores dos que os estabelecidos. Eles disseram ainda que estes agentes poderiam ter sidos financiados pela indústria ricinoquímica para dificultar a competição. Estes pontos foram ressaltados nos trabalhos de Silva et al. (2014) e Finco \& Doppler (2011).

Com relação à atuação dos intermediários no NPSR, observou-se que esta se limitou apenas a aquisição mamona, não financiando a produção como ocorre em outras regiões, como salientou César (2009). Diante da percepção dos entrevistados e das respostas obtidas, o subfator atuação dos intermediários foi percebido como neutro.
Em qualquer atividade econômica, o acesso ao crédito é importante para o desenvolvimento de negócios, uma vez que possibilita o financiamento da capacidade produtiva e consequente aumento da produtividade. No NP$\mathrm{SR}$, os entrevistados relataram que não existe uma linha de crédito específica para o financiamento da mamona, mas este pode ser feito através do PRONAF, no qual, grande parte dos agricultores familiares local está habilitada a pleiteá-lo para investimento em custeio e comercialização.

Apesar da existência das linhas de crédito do PRONAF, os entrevistados alertaram que o acesso a elas é muito restrito e o financiamento das atividades relacionadas à produção de mamona acaba sendo feita pelos próprios agricultores.

\subsubsection{Direcionador Ambiente institucional e seus subfatores}

Neste direcionador, foi avaliada a percepção dos entrevistados com relação à fiscalização por parte dos órgãos responsáveis, a assistência prestada pelos órgãos governamentais e as políticas públicas para a inserção dos agricultores familiares no PNPB (Figura 6).

Com relação à fiscalização, os entrevistados apontaram a figura do articulador como único agente fiscalizador, embora este não seja seu papel. Eles disseram desconhecer qualquer iniciativa montada por órgãos governamentais ou membros do Grupo de Trabalho para monitorar ou verificar eventuais descumprimentos dos contratos por parte das cooperativas e da empresa de produtora de biodiesel que atuaram no NP-SR. Este subfator foi então classificado como muito desfavorável.

Quanto à assistência prestada pelos órgãos governamentais, os entrevistados afirmaram que esta foi quase nula, limitando-se à oferta de infraestrutura necessária a realização de eventos para mobilização dos agricultores, na elaboração de projetos de acesso ao crédito do Pronaf e emissão da DAP. Devido ao pouco envolvimento com as questões relacionadas ao biodiesel no NP-SR, este subfator foi percebido com desfavorável.

Já com relação às políticas públicas para a inserção dos agricultores familiares na CPB, observou-se que os entrevistados desconhecem questões relacionadas ao marco regulatório do biodiesel. Fato também observado por Olave et al. (2017) e De Oliveira et al. (2019). Entretanto, avaliam como favorável qualquer iniciativa que traga melhoria no nível de vida dos agricultores familiares, fazendo com que este subfator obtivesse a nota positiva e fosse classificado como favorável. No geral, o direcionador ambiente institucional foi classificado como desfavorável. 
5.1.7 Análise Geral dos Direcionadores e Proposições para melhorar a Competitividade dos Agricultores Familiares do NP-SR na Cadeia Produtiva do Biodiesel

Dos seis direcionadores constituídos (insumos, tecnologia de produção, gestão, estrutura de produção, relações de mercado e ambiente institucional) somente o direcionador "estrutura de produção" foi classificado como positivo. Isso devido à boa avaliação recebida pelos subfatores disponibilidade de terras e das condições edafoclimáticas propícias ao cultivo da mamona no NP-SR. As médias obtidas pelos subfatores e seus respectivos pesos foram utilizados para obter a média ponderada dos direcionadores de competitividade, apresentados na Figura 7.

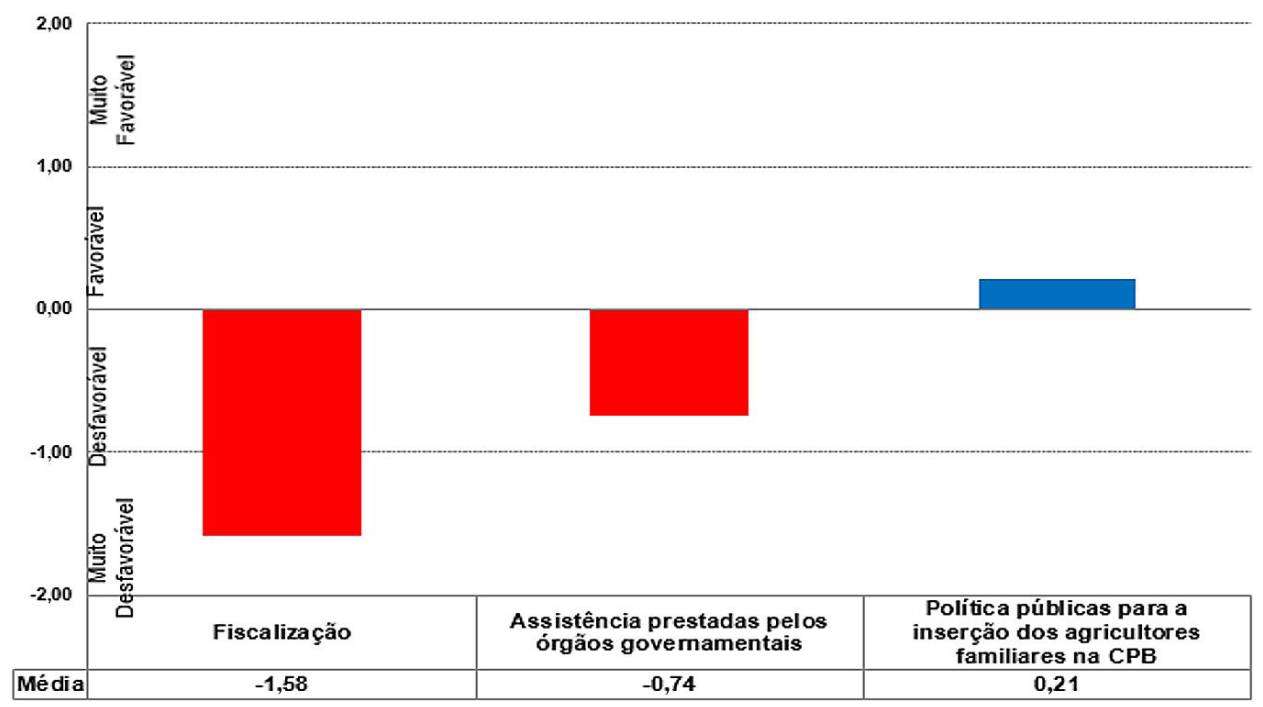

FIGURA 6 - Avaliação dos subfatores do direcionador de competitividade ambiente institucional Fonte: Elaborado pelos autores (2019)

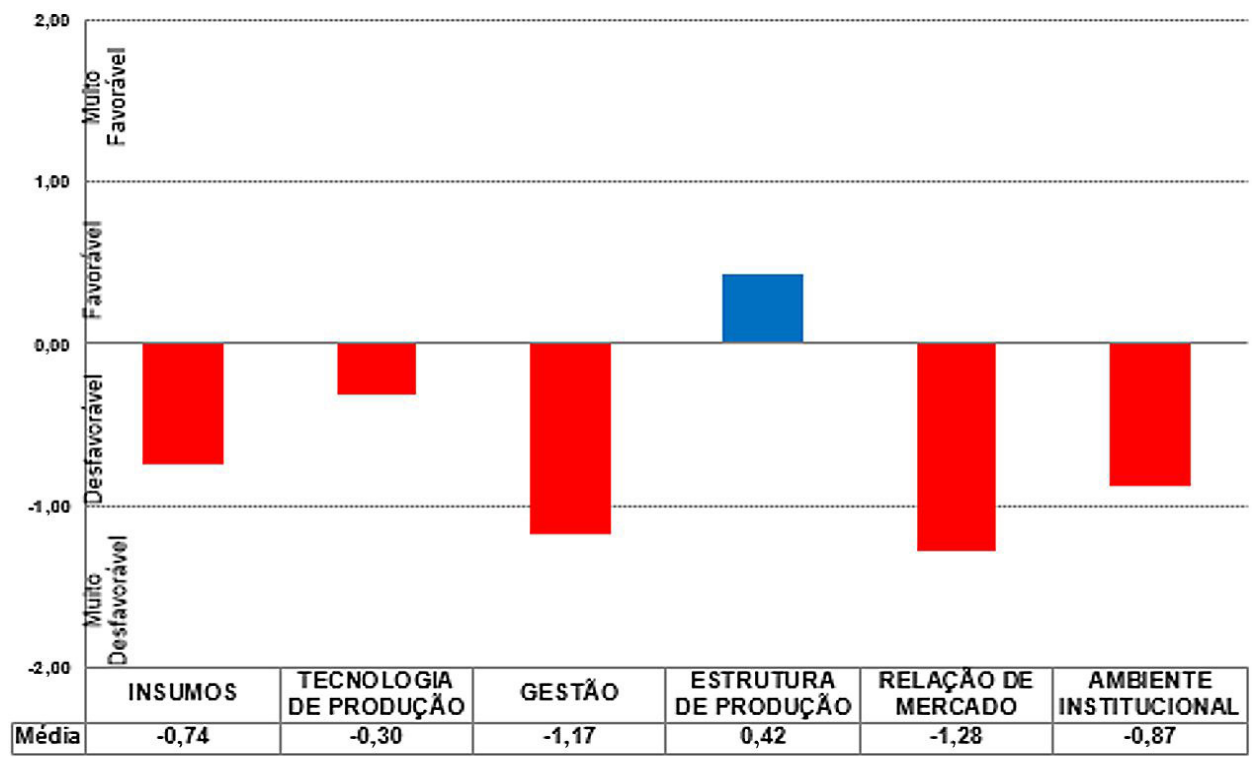

FIGURA 7 - Avaliação geral dos direcionadores de competitividade do NP-SR Fonte: Elaborado pelos autores (2020) 
Neste contexto, as proposições que podem ser sugeridas para superar os entraves encontrados no NP-SR estão descritas no Quadro 2.

Numa visão relacionada à Gestão de Projetos, os direcionadores Insumos e Tecnologia de Produção, apesar de poderem ser considerados fatores internos, ou seja, teoricamente poderiam ser controlados pelos pequenos agricultores, estes ainda necessitariam de apoio externo, para aquisição, inicialmente de sementes, e, principalmente de implementos agrícolas, como maquinário, defensivos agrícolas e assistência técnica. Para estes casos, o Governo deveria ser o principal parceiro. Já para melhoria da Gestão, seria necessário firmar parcerias com órgãos híbridos, como o SENAR e o Serviço Brasileiro de Apoio às Micro e Pequenas Empresas (SEBRAE), que oferecem consultoria e apoio técnico, mediante a solicitações e apresentação de projetos.

QUADRO 2 - Proposições para superar os entraves no NP-SR

\begin{tabular}{|c|c|c|}
\hline Direci & Entraves Identificados & Proposições \\
\hline \multirow{3}{*}{ Insumos } & Atrasos na distribuição de sementes. & $\begin{array}{l}\text { Desburocratização das ações relacionadas à logística de } \\
\text { distribuição das sementes por parte usinas de biodiesel. }\end{array}$ \\
\hline & $\begin{array}{l}\text { Utilização insuficiente de insumos como } \\
\text { adubos e defensivos agrícolas. }\end{array}$ & $\begin{array}{l}\text { O técnico agropecuário precisa ressaltar as vantagens inerentes } \\
\text { da utilização destes insumos para o aumento da produtividade. }\end{array}$ \\
\hline & $\begin{array}{l}\text { Número de máquinas insuficientes para a } \\
\text { demanda. }\end{array}$ & $\begin{array}{l}\text { Maior organização dos agricultores e Criação de um sistema de } \\
\text { roteirização para melhorar a distribuição das máquinas e reduzir } \\
\text { o custo de movimentação. }\end{array}$ \\
\hline $\begin{array}{l}\text { Tecnologia de } \\
\text { Produção }\end{array}$ & $\begin{array}{l}\text { Utilização de técnicas de produção de baixa } \\
\text { eficiência: manejo inadequado do solo, } \\
\text { utilização insuficiente de insumo e baixo nível } \\
\text { de mecanização }\end{array}$ & $\begin{array}{l}\text { Disponibilizar informações para os agricultores familiares através } \\
\text { do fortalecimento de ações educativas. } \\
\text { Investimento por parte das empresas produtoras biodiesel em } \\
\text { maquinários, análises de solo e contratação de assistência técnica. }\end{array}$ \\
\hline \multirow{3}{*}{ Gestão } & Gestão deficiente dos estabelecimentos rurais. & $\begin{array}{l}\text { Estabelecimento de parcerias de órgão público de fomento } \\
\text { à agricultura ou das empresas produtoras de biodiesel com } \\
\text { o Serviço Nacional de Aprendizagem Rural (SENAR) para } \\
\text { estimular boas práticas de gestão. }\end{array}$ \\
\hline & $\begin{array}{l}\text { Falta de organização produtiva dos agricultores } \\
\text { familiares em cooperativas e associações }\end{array}$ & $\begin{array}{l}\text { Estimular a organização da produtiva dos agricultores familiares } \\
\text { do NP-SR em cooperativas ou associações. }\end{array}$ \\
\hline & Número limitado de técnicos agropecuários. & Maior investimento em contratação de técnicos agropecuários. \\
\hline \multirow{2}{*}{$\begin{array}{l}\text { Estrutura de } \\
\text { Mercado }\end{array}$} & $\begin{array}{l}\text { Indisponibilidade ou custo elevado para } \\
\text { contratação de mão de obra temporária. }\end{array}$ & $\begin{array}{l}\text { Investimento em mecanização de algumas atividades de } \\
\text { produção. }\end{array}$ \\
\hline & Falta de infraestrutura logística. & $\begin{array}{l}\text { Melhoria no sistema de roteirização de transporte da safra para } \\
\text { atender a todos os agricultores e aluguel de armazéns. }\end{array}$ \\
\hline \multirow{4}{*}{$\begin{array}{l}\text { Relação de } \\
\text { Mercado }\end{array}$} & $\begin{array}{l}\text { Relações entre agricultores familiares do NP- } \\
\text { SR e as cooperativas }\end{array}$ & $\begin{array}{l}\text { Melhor organização produtiva dos agricultores familiares do } \\
\text { NP-SR. }\end{array}$ \\
\hline & $\begin{array}{l}\text { Quebra de contrato por parte das cooperativas, } \\
\text { usinas e agricultores. }\end{array}$ & $\begin{array}{l}\text { Maior fiscalização tanto por parte dos órgãos públicos } \\
\text { competentes como das empresas produtoras que firmam acordos } \\
\text { com as cooperativas. }\end{array}$ \\
\hline & $\begin{array}{c}\text { Demora na liberação do pagamento da compra } \\
\text { de matéria-prima. }\end{array}$ & Agilidade na liberação do pagamento. \\
\hline & Dificuldade de acesso a linhas de crédito. & $\begin{array}{c}\text { Melhoria na oferta de linha de crédito para mamona e } \\
\text { desburocratização para liberação do dinheiro. }\end{array}$ \\
\hline \multirow{2}{*}{$\begin{array}{l}\text { Ambiente } \\
\text { Institucional }\end{array}$} & $\begin{array}{l}\text { As cooperativas fecham contratos de compra } \\
\text { e venda, mas não os disponibilizam para o } \\
\text { sindicato e nem para os agricultores. }\end{array}$ & Fortalecer as ações de fiscalização. \\
\hline & $\begin{array}{l}\text { Pouco apoio por parte de instituições públicas } \\
\text { de fomento à agricultura. }\end{array}$ & $\begin{array}{l}\text { Reestruturação do grupo de trabalho responsável pelas ações } \\
\text { relacionadas ao biodiesel no NP-SR }\end{array}$ \\
\hline
\end{tabular}

Fonte: Elaborado pelos autores (2020)

Organizações Rurais \& Agroindustriais, Lavras, v. 23, e1752, 2021 
Já os direcionadores Estrutura e Relação de Mercado e Ambiente Institucional, exigem ações governamentais mais eficientes para seu perfeito funcionamento, especialmente, quando há necessidade de maior fiscalização, fornecimento de infraestrutura e acesso a linhas de crédito voltadas à produção. Desse modo, apesar de existir a necessidade de organização interna dos agricultores, a atuação do governo é fundamental.

\section{CONSIDERAÇÕES FINAIS}

OPNPB está baseado em aspectos de sustentabilidade econômica, ambiental e social. Com relação a este último aspecto, o programa inovou ao permitir que o biodiesel fosse produzido a partir de diferentes fontes de oleaginosas disponíveis em todo território nacional, aproveitando assim as aptidões regionais.

Outra inovação foi a obrigatoriedade da agricultura familiar na cadeia produtiva do biodiesel com o intuito de gerar emprego e renda e contribuir para o desenvolvimento de áreas carentes do território nacional, como o núcleo de produção de mamona do município de Serra do Ramalho (NP-SR), localizado no Território de Identidade Velho Chico no semiárido baiano.

O advento do NP-SR, trouxe vários benefícios para a comunidade, tais como: maior profissionalização da mão de obra que interage diretamente com a lavoura, por conta do contato com a assistência técnica especializada; acesso a conhecimentos sobre administração de entidades, auxiliando a profissionalizar o processo de gestão da produção; e maior interação social entre os membros da comunidade.

Entretanto, apesar do núcleo ter se mostrado produtivo nas primeiras safras após a sua estruturação, rapidamente entrou em declínio. Contribuíram para a deterioração do NP-SR o jogo de interesses que deixou os agricultores familiares fragilizados diante das empresas produtoras de biodiesel, comprometendo assim a organização da sua base produtiva.

Além do mais, uma série de fatores negativos contribuiu para a formação de entraves que impactam diretamente na produção de mamona, comprometendo sua competitividade, fazendo com que o programa de biodiesel não seja sustentável até o presente momento no NP-SR. Destes, destaca-se o não cumprimento dos contratos por parte das empresas produtoras de biodiesel com os agricultores familiares do NP-SR.
Faz-se necessário redefinir os papeis dos atores envolvidos, estimular boas práticas de gestão entre os agricultores familiares, investir na melhoria do nível tecnológico e da assistência técnica prestada e aumentar a fiscalização por parte dos agentes públicos. Desta forma, talvez o núcleo tenha uma nova oportunidade de se reerguer e também superar a grave seca que ocorreu entre 2012 e 2015.

\section{AGRADECIMENTOS}

Ao Conselho Nacional de Desenvolvimento Científico e Tecnológico (CNPq) pelo Projeto de Pesquisa no Edital Universal 01/2016 (Processo n. 428065/2016-3) e FAPESB - Edital Jovem Cientista.

\section{REFERÊNCIAS}

Abicht, A. de M., Ceolin, A. C., Pereira, P. R. R. X. \& Corrêa, A. O. de F. (2014). As relações entre o produtor rural, a cooperativa e a indústria na produção do biodiesel sob a ótica da ECT. Redes (St. Cruz Do Sul Online), 19(1), 93-109. https://doi.org/10.17058/ REDES.V19I1.2197

Batalha, M. O., Buainain, A. M. \& Souza Filho, H. M. de. (2005). Tecnologia de gestão e agricultura familiar. In $\mathrm{H}$. M. de Souza Filho (Ed.), Gestão integrada à agricultura familiar (p. 359). Edufscar.

Batalha, M. O. \& da Silva, A. L. (2008). Gerenciamento de Sistemas Agroindustriais: definições, especificidades e correntes metodológicas. In M. O. Batalha (Ed.), Gestão Agroindustrial (3rd ed., p. 770). Atlas.

Batalha, M. O. \& Souza Filho, H. M. de. (2009). Agronegócio no Mercosul: uma agenda para o desenvolvimento. Atlas.

Borges, A. C. P., Silva, M. S., Alves, C. T. \& Torres, E. A. (2016). Renewable energy: a contextualization of the biomass as power supply. REDE: Revista Eletrônica Do PRODEMA, 10(02), 23-36. https://doi.org/10.22411/ rede2016.1002.02

MDA, Pub. L. No. MDA 2012 (2012).

Brune, S. (2010). The Brazilian Biodiesel Program $(P N B P)$ and Social inclusion [Wageningen University]. https://edepot.wur.nl/166666 
Campos, M. B. N., Silva Júnior, A. G. da, Perez, R., de Jesus, R. B. \& Silva, N. D. (2009). Análise da competitividade da cadeia da produção de oleaginosas oriundas da agricultura familiar na região de abrangência da Coopaf. Bahia Análise \& Dados, 4(18), 687-697. https://www.sei.ba.gov.br/index.php?option=com content $\&$ view $=$ article $\&$ id $=74 \&$ Itemid $=284$

Cartaxo, W. V., Beltrão, N. E. de M., Vale, L. S. do \& Silva, J. L. da C. (2011). UNIDADES DE TESTE E DEMONSTRAÇÃO/ESCOLA DE CAMPO: ESTRATÉGIA PARA APROPRIAÇÃO TECNOLÓGICA NA AGRICULTURA FAMILIAR. Cadernos de Ciência \& Tecnologia, 28(2), 625-634.

César, A. da S. \& Batalha, M. O. (2010). Biodiesel production from castor oil in Brazil: A difficult reality. Energy Policy, 38(8), 4031-4039. https://doi.org/10.1016/J. ENPOL.2010.03.027

César, A. da S. \& Batalha, M. O. (2011). Análise dos direcionadores de competitividade sobre a cadeia produtiva de biodiesel: o caso da mamona. Production, 21(3), 484497. https://doi.org/10.1590/S0103-65132011005000039

Conejero, M. A., César, A. D. S. \& Batista, A. P. (2017). The organizational arrangement of castor bean family farmers promoted by the Brazilian Biodiesel Program: A competitiveness analysis. Energy Policy, 110, 461-470. https://doi.org/10.1016/J.ENPOL.2017.08.036

De Oliveira, F. C. \& Coelho, S. T. (2017). History, evolution, and environmental impact of biodiesel in Brazil: A review. Renewable and Sustainable Energy Reviews, 75, 168-179. https://doi.org/10.1016/J.RSER.2016.10.060

De Oliveira, F. C., Lopes, T. S. A., Parente, V., Bermann, C. \& Coelho, S. T. (2019). The Brazilian social fuel stamp program: Few strikes, many bloopers and stumbles. Renewable and Sustainable Energy Reviews, 102, 121128. https://doi.org/10.1016/J.RSER.2018.12.011

dos Santos Alves, C. E., Belarmino, L. C. \& Padula, A. D. (2017). Feedstock diversification for biodiesel production in Brazil: Using the Policy Analysis Matrix (PAM) to evaluate the impact of the PNPB and the economic competitiveness of alternative oilseeds. Energy Policy, 109(June), 297-309. https://doi.org/10.1016/j.enpol.2017.07.009

EMBRAPA. (2012). Mamona. Mamona. www.cnpa. embrapa.br/produtos/mamona
EPE. (2019). Balanço Energético Nacional, 2019 - Ano Base 2018. http://www.epe.gov.br/sites-pt/publicacoesdados-abertos/publicacoes/PublicacoesArquivos/ publicacao-377/topico-470/Relatório Síntese BEN 2019 Ano Base 2018.pdf

Estrela, E. S. (2006). Um Caso de deslocamento compulsório: O Projeto Especial de Colonização Serra do Ramalho Bahia. CONGRESSO LATINO AMERICANO DE SOCIOLOGIA RURAL.

Farina, E. M. M. Q. (1999). Competitividade e coordenação de sistemas agroindustriais: um ensaio conceitual. Gestão \& Produção, 6(3), 147-161. https://doi.org/10.1590/ S0104-530X1999000300002

Ferraz, J. C., Kupfer, D. \& Haguenauer, L. (1995). Made in Brazil: desafios competitivos para a indústria. Rio de Janeiro: Campus, August 2018, 386.

Finco, M. V. A. \& Doppler, W. (2011). The brazilian biodiesel program and regional development: cases from northern Brazil. Redes (St. Cruz Do Sul Online), 16(3), 215-241. https://doi.org/10.17058/REDES.V16I3.1887

Guarieiro, L. L. N., Torres, E. A. \& Bitencourt, J. A. (2011). Energia Verde. In A. Ivanissevich \& Â. da C. Pinto (Eds.), Química Hoje (1st ed., pp. 118-125). Instituto Ciência Hoje.

IBGE. (2021). IBGE | Cidades@ | Bahia | Serra do Ramalho | Panorama. Dados Estatísticos de Serra Do Ramalho. https://cidades.ibge.gov.br/brasil/ba/serra-doramalho/panorama

Lima, Â. M. F., Torres, E. A., Kiperstok, A. \& Silva, M. S. (2019). TECHNOLOGY MAPPING AND CHARACTERIZATION OF BIODIESEL USING COTTONSEED AND PALM OIL IN THE STATE OF BAHIA, BRAZIL. Revista Em Agronegócio e Meio Ambiente, 12(3), 1143-1165. https://doi. org/10.17765/2176-9168.2019V12N3P1143-1165

Lima, M. A., Mendes, L. F. R., Mothé, G. A., Linhares, F. G., de Castro, M. P. P., da Silva, M. G. \& Sthel, M. S. (2020). Renewable energy in reducing greenhouse gas emissions: Reaching the goals of the Paris agreement in Brazil. Environmental Development, 33, 100504. https:// doi.org/10.1016/J.ENVDEV.2020.100504 
Lopes, A. N., Rocha, A. M., Silva, M. S. \& Soares, P. M. (2019). Perfil patentário da Camelina Sativa com potencial para produção de biodiesel. Revista Tecnologia e Sociedade, 15(37), 389-402. https://doi.org/10.3895/ RTS.V15N37.9665

MDA. (2012b). SIT - Sistema de Informações Territoriais. Sistema de Informações Territoriais. http://sit.mda.gov. br/mapa.php

Moreno-Pérez, O. M., Marcossi, G. P. C. \& OrtizMiranda, D. (2017). Taking stock of the evolution of the biodiesel industry in Brazil: Business concentration and structural traits. Energy Policy, 110, 525-533. https://doi. org/10.1016/J.ENPOL.2017.09.001

Olave, M. E. L., Vaz, V. H. da S. \& Brazil, O. A. V. (2017). Análise do desenvolvimento de organizações públicas a partir da governança de uma rede de cooperação para a produção de biodiesel em Sergipe. Redes (St. Cruz Do Sul Online), 22(3), 170-198. https://doi.org/10.17058/REDES.V22I3.9736

Pinto, A. C., Guarieiro, L. L. N., Rezende, M. J. C., Ribeiro, N. M., Torres, E. A., Lopes, W. A., Pereira, P. A. de P. \& Andrade, J. B. de. (2005). Biodiesel: an overview. Journal of the Brazilian Chemical Society, 16(6B), 13131330. https://doi.org/10.1590/S0103-50532005000800003

Ribeiro, E. C. B., Moreira,A. C., Ferreira, L. M. D. F. \& da Silva César, A. (2018). Biodiesel and social inclusion: An analysis of institutional pressures between biodiesel plants and family farmers in southern Brazil. Journal of Cleaner Production, 204, 726-734. https://doi.org/10.1016/J.JCLEPRO.2018.09.085

Rocha, A. M., Quintella, C. M., Torres, E. A. \& Silva, M. S. (2015). Biodiesel in Brazil: science, technology and innovation indicators. International Journal of Technology Management, 69(3/4), 246. https://doi.org/10.1504/ IJTM.2015.072984

Sánchez, A. S., Almeida, M. B., Torres, E. A., Kalid, R. A., Cohim, E. \& Gasparatos, A. (2018). Alternative biodiesel feedstock systems in the Semi-arid region of Brazil: Implications for ecosystem services. Renewable and Sustainable Energy Reviews, 81, 2744-2758. https:// doi.org/10.1016/J.RSER.2017.06.080

SEAGRI. (2012). Cultura - Mamona. Cultura Da Mamona. http://www.seagri.ba.gov.br/Mamoneira
SEI. (2010). SEI - Estatísticas dos Municípios Baianos. Estatísticas Dos Municípios Baianos. https://www.sei.ba.gov.br/index.php?option=com content\&view=article\&id=2441\&Itemid $=284$

Shultz, G., Zanetti, C. \& Waquil, P. D. (2011). Análise da competitividade das cadeias produtivas agroindustriais. In G. Schultz \& P. D. Waquil (Eds.), Políticas Públicas e Privadas e competitividade das cadeias agroindustriais (p. 80). UFRGS. http://hdl.handle.net/10183/214156

Silva, M.F.M.M.(2009). Sistemas produtivos da mamona para produção de matéria-prima para biodiesel na Região Nordeste do Brasil [Universidade de Brasília]. https://bdtd.ibict.br/ vufind/Record/UNB_f61e078a3ee3b667d84332bff67e1597

Silva, M. S., Fernandes, F. M., Teixeira, F. L. C., Torres, E. A. \& Rocha, A. M. (2014). Biodiesel and the "Social Fuel Seal" in Brazil: Fuel of Social Inclusion? Journal of Agricultural Science, 6(11). https://doi.org/10.5539/jas.v6n11p212

Silva, M. S., Teixeira, F. L. C., Torres, E. A., Matos, F. F. \& Machado, A. R. (2014). Family Farming and Biodiesel: The Difficulties of Socioeconomic Inclusion in the Northeast of Brazil. Journal of Agricultural Science, 6(7), 231-252. https://doi.org/10.5539/jas.v6n7p231

Silva, M. S., Teixeira, F. L. C., Torres, E. A., Rocha, A. M., Freires, F. G. M., Santos, T. B. \& De Jong, P. (2014). Biodiesel in Brazil: A Market Analysis and Its Economic Effects. Journal of Agricultural Science, 6(8), p160. https://doi.org/10.5539/jas.v6n8p160

Singh, D., Sharma, D., Soni, S. L., Sharma, S., Kumar Sharma, P. \& Jhalani, A. (2020). A review on feedstocks, production processes, and yield for different generations of biodiesel. Fuel, 262, 116553. https://doi.org/10.1016/J.FUEL.2019.116553

Van Duren, E., Martin, L. \& Westgren, R. (1991). Assessing the Competitiveness of Canada's Agrifood Industry. Canadian Journal of Agricultural Economics/ Revue Canadienne d'agroeconomie, 39(4), 727-738. https://doi.org/10.1111/J.1744-7976.1991.TB03630.X

Zheng, T., Wang, B., Rajaeifar, M. A., Heidrich, O., Zheng, J., Liang, Y. \& Zhang, H. (2020). How government policies can make waste cooking oil-to-biodiesel supply chains more efficient and sustainable. Journal of Cleaner Production, 263, 121494. https://doi.org/10.1016/J.JCLEPRO.2020.121494 